\title{
Anthropocentric Production Systems are Socio-Technological Innovations
}

\author{
Dr. W. Wobbe \\ European Commission \\ Rue de la Loi 200, B-1049 Brussels, Belgium. \\ Tel. +32.2.295.08.79, Fax. +32.2.299.49.91
}

\begin{abstract}
The globalization of the economy demands increased change and results in relocation of manufacturing sites. In order to gain in world competition and to create welfare for regions the leading economies are creating continuous innovations. This paper explains why expanding customized quality products require Anthropocentric Production Systems (APS) in the manufacturing sector and that they are based on social innovations aided by technical ones. It is argued that flexible manufacturing needs a specific factory organization to be complemented by adequate human skills and adapted technologies
\end{abstract}

\section{Keywords}

Anthropocentric production systems, manufacturing, organization, innovation, adapted technologies

\section{BACKGROUND - GLOBAL CHANGE OF PRODUCTION PARAMETERS}

This decade, the high wage based industrialized countries have come under threat in their manufacturing operations by the newly industrializing countries and now possibly by Eastern European ones.

Particularly in the European Union factory close-downs and rising unemployment are filling the headlines. The fear of economic growth without employment in manufacturing is increasing. It seems that the new notion of "lean production" means firing people. Factory automation has always meant higher output with fewer people i.e. raising labour productivity in growing markets. Now automation has to cope with volatile markets and capital productivity. Today, large technological investments might be more detrimental to the survival of corporations than too many people on board. However, few discussions can be found about this aspect.

While in Europe lean production concepts have been increasingly applied over recent years, in Japan a debate about post-lean models has emerged (Fujimoto 1994). The automobile industry in Japan in particular has problems in recruiting skilled labour 
because of high individual work pressure. Contrary to Western observers believing that Japan has already introduced group work, polyvalent operations and decentral competence, only now are their firms beginning to discuss such methods to increase flexibility and efficiency in order to respond better to shrinking market opportunities.

\section{INNOVATION: TECHINICAL AND SOCIAL COMPLEMENTARITY}

The race for industrial leadership is governed by innovations in order to win world market shares. The term "innovation" is too often associated with technological innovation and only accepted as such. The fact that the success of technological innovation is closely associated with social innovation is overlooked. If a technological innovation is not accepted - whether for ethical, cultural, behavioural or educational reasons - it will be a market failure.

This is very evident for a product. But it is also the case for the manufacturing sphere. For example, a computer might not be used because its entry procedure is too complicated. The control of CNC machines could be underutilised because it is too abstract and the worker is used to geometrical drawings or three-dimensional understanding. A planning programme might be abandoned because it is too rigid and leaves no decision space for the scheduler.

Here again the potential of the technology has to be developed to adapt to the social characteristics of behaviour rather than urging people to adapt to a mathematical logic which differs from their working perception.

In any extent, working behaviour is a fundamental fact. Technological innovations are often developed in their own logic i.e. logic of the developer rather than the customer. It forces the customer into an innovation in his behaviour - to learn special procedures, into technical communication instead, to allow for social cooperation etc. Resistance to that special enforcement of working behaviour, or social innovation is often overlooked. This is a "technocentric view", meaning that the technological innovation is the invariable and the social is the variable. A more enlightened technological development would take place the other way round and could be called "anthropocentric", i.e. trying to adapt the technology to the customer's needs and abilities. This leaves room within a firm's organisation for flexible behaviour towards quick reaction to market changes and to market responses with improved products.

\subsection{The new customised quality economy.}

During the last decade, a market shift in customised quality products has grown at the cost of standardised mass products. European industries based on mass products and price competition have lost out to the Far East and might in future face competition from Eastern Europe. In Western Europe, the increase in product variants, quality features, small batch sizes and a decrease in product life-cycles and repeat orders has dramatic consequences for management and organisation in the manufacturing industries. During the 1980s, it has become evident that demand flexibility cannot be met by new technologies alone.

For manufacturing, it is relevant to understand that product markets are in transformation. This market shift is the economic background for the success or failure of manufacturing concepts.

The more affluent the Western societies have become, the more customised products are 
demanded. Quality features have come more and more into play, not only that of reliability but also those of additional functions and of design. While the cheap and price competitive products are increasingly produced in low wage countries, the markets for customised quality products are expanding throughout Europe. This increase of the customised quality economy has a high impact on manufacturing.

The example of a large British electro-mechanical producer may serve as an illustration of developments in industry. Not all the corporation's efforts to reduce the variants have been successful. On the contrary. The product variants have steadily been increased, and at the same time the demand for quality upgrading has increased in parallel. On the other hand, the lifecycles of products have decreased and with them, the repeat orders. Also, the batch sizes have been reduced dramatically due to customer demand, to minimise stocks, and deliver the right portions when needed. In other manufacturing industries, and even in chemicals, a similar trend is observed.

These contradicting trends in manufacturing, a dilemma in the philosophy of price competition, can only be handled by a different way of manufacturing from that of applying mass production principles.

\subsection{The clash between markets and manufacturing concepts}

Expanding markets and world competition have led to enforced division of labour in this century and to taylorist and fordist principles of work organisation. Achieving maximal scale of production via specialisation and automation were the guiding concepts for managers. Increased labour specialisation and automation have been complementary processes.

When, during the 1970s and 1980s, fragmentation of markets and product complexity grew and production flexibility became a threat, the computer aided technologies seemed to offer a solution to cope with this challenge in manufacturing. Therefore, in these two decades the technological imperative, the technocentric manufacturing vision, became dominant in managers' minds and in public support for R\&D. At the end of the 1980s, the first critical conclusions were made by researchers observing the diffusion pattern of the computer-aided technologies. These resulted in the following:

-industrial robots, the symbols of industrial automation, are far beyond expectation in industrial development;

-flexible manufacturing systems (FMS) are hardly economic if applied in tayloristic forms of work organisation (Haywood and Bessant, 1990);

-information technology in manufacturing had been applied very differently according to social constellations (Campbell et al., 1989);

-in the Danish context, a paradox in increasing technology application and diminishing productivity has been observed;

- on the contrary, in Japan the capital productivity has always been an issue complementary to organisational aspects (Kageyama, 1993).

In conclusion, the manufacturing concepts inspired by information technology aiming at the unmanned automated factory have been put into question. The complex interplay between man, technology and organisation and its management has been recognised as a system.

In the 1990s, influenced by the MIT study about 'lean production' (Womack et al., 1990) 
and the EU on APS (Lehner, 1991), it has become clear that the manufacturing organisation, the use of skilled and competent labour and a proper management of this system are fundamental to the problem solution witnessed. Therefore, manufacturing is in the course of shifting from its technocentric focus to one that is anthropocentric and collaborative.

\section{ANTHROPOCENTRIC PRODUCTION SYSTEMS (APS)}

The anthropocentric production systems (APS) have been developed in order to cope with the customised quality economy. In general terms, their principles or their Leitbild in organising the manufacturing process could be described in a nutshell as follows (Wobbe 1991):

-decentralised production units;

-comprehensive use of human abilities and performance;

-permanent learning of the work force and facilitating corporate structures;

-cut-backs in the division of labour;

-collaborative forms of organisation;

-adapted technologies.

In order to make these principles more concrete, their implications for designing production systems are made clear in the following subsections, which deal with various levels within an organisation and the technological requirements.

\subsection{The organisational design of APS on different levels inside the firm.}

At the factory level the guiding principle of APS points to decentralised production units. Plants can be organised into different product shops and be regarded as companies within a company. The main guiding principle would be the delegation of responsibility to lower levels to provide more autonomy.

The intendepartmental relationships and their collaborative functions are of central importance. In the course of growth of industrial enterprises, a strong departmentalisation has occurred. Management has been confronted with coordination problems because departments have acted as separate entities. This separation has consequently created limitations to productivity, integration of firms, and led to an unproportional growth of indirect labour.

The Leitbild for APS is to increase day-to-day cooperation between 'experts' at all levels: the experts in executing the shopfloor work and the experts who have planned this work: the experts who make the decisions and give the orders and the experts who have asked for the order: the experts who run the machine and the experts who programme it. In practice, this means the instigation of face-to-face dialogue between designers, planners and manufacturing workers. This would lead, for example, to an interactive programming process between technician and worker on very complex parts, or the intensification of collaboration and early agreements between the business departments and the shopfloor concerning planning and scheduling. Cooperative relationships between white-collar and blue-collar workers are central.

The working-group level might not even exist in strong hierarchical organisations. Therefore, one of the central innovations of the last two decades in manufacturing has been the introduction of working groups in the automobile industry as well as in mechanical 
engineering or chemical plant supervision and maintenance. The case of Volvo has become the most famous example with its semi-autonomous assembly groups. These organisational developments have given rise to completely new concepts of logistics.

Another case is the so-called 'production island ' where discrete parts of manufacturing are grouped around a family of parts. The underlying principle in all these cases is the transfer of a broad range of functions, occupations and decision space to the group and to ensure that most members can cope with it.

The APS design for the work place demands a broad range of measures to ensure skilled and collaborative work. The work place design has not only to create optimal work conditions but also to provide an environment which stimulates innovation, learning and collaboration based on a range of competence. Besides the design of the work organisation, the $\mathrm{man} / \mathrm{machine}$ relationship is challenged by software design.

In more detail, in highly automated areas the integration of job tasks, i.e. programming, scheduling, maintenance, processing etc. are central. In the assembly areas the work enrichment towards hybrid assembly is a way of work design. In lowly automated areas of batch production, work enrichment by planning, scheduling and maintenance tasks, as well as job rotation, are possible actions which can be taken.

\subsection{APS requirements for technology}

In the same way as existing examples of 'living' implemented APS organisations can be found, there already exists pieces of APS technology. For example, the shopfloor programming package 'WOP', developed in the German programme 'Fertigungstechnik' is already on the market.

The same holds true for the design sketchpad and the group-supporting scheduling system. Although there are concrete examples of software and hardware for APS technologies, there is still a broad scope for technological development. The core of these APS technologies is to be found mainly in the software component and its potential to aid APS structures. In contrast, the hardware is the less important part in APS technologies.

It has to be borne in mind that APS technology alone does not guarantee APS structures. These have to be achieved by organizational measures, and steps towards APS can even be achieved without APS technology. Thus, the technology has to be considered merely as a tool to work with. It is important to allow for collaborative workshop programming and interactive communicative tools with the design and technical office, but the technology alone is no guarantee that such working patters will actually occur. Finally, it has to be assured that the technology does not block organizational measures, but assists them. New technology has to be developed for the full potential of APS to be realised.

Table 1 lists APS technology and technologies which can be used in APS structures, as well as the research and development areas which should be realized. Research and development are needed to elaborate 'tools' applied in the workplace which are IT-based but equipped with an analogue user surface, which is highly transparent for information, decision and control purposes within the manufacturing process. The man/machine interface has to work with elaborated symbolic representations which can be composed to make up complete pictures. Therefore, new vision systems and adaptable natural language interfaces are required to support the analogue and to guide the working behaviour of the user. The devices should also include learning supports concerned with the systems as well as with the working process. 
Table 1 APS technology

\begin{tabular}{ll}
\hline Level & Technology \\
\hline Work place & * shopfloor programming systems for machine tools and \\
& robots \\
& *decision support systems \\
& *analogue user support mechanism to control the \\
& manufacturing process \\
& *symbolic representations of complete pictures for \\
& information, processing and decisions \\
& *skill supporting and learning techniques \\
& *scheduling and planning systems for group work \\
& *computer aided cooperative work techniques for \\
Group & information, planning and decisions \\
& *IT systems to facilitate interactions and dialogue between \\
& office and shopfloor \\
Interdepartmental & *transportable analogue design sketch pads \\
& *information systems to support network organisational \\
& structures \\
Factory & *adaptable and natural language human/computer interfaces \\
& *highly transparent support systems for collective and \\
General & individual decision making \\
& *new visual symbolic representation systems
\end{tabular}

At the collaboration level between different departments or groups, new software systems have to be developed. They will aid the collaboration through information and decision support, rendering the overall cooperation process transparent and thereby permitting simulation and interaction.

-team work at all levels of production;

-blue/white-collar communication;

-interdepartmental cooperation;

-collaborative industrial relations;

-cooperation in the supply chain.

These requirements touch attitudes, values, behaviour, social distinction, power and influence in corporations. They are the core of a given industrial culture - how people and organisations deal with each other - and immediately concern the management of a firm.

Taking into account the difficult social change process, the question is where does Europe stand with the introduction of organisationally advanced manufacturing. Many European firms are modernising their production on the lines of APS, particularly leading firms (Brandt, 1991). However, the overwhelming majority has not been affected by modern developments. Also, a split can be observed between advanced and less advanced manufacturing countries in Europe pointing to the danger of widening the welfare gap between those countries. 


\section{THE INTRODUCTION OF ADVANCED MANUFACTURING IN THE EUROPEAN UNION}

The MONITOR-FAST programme has carried out research on the assessment of the socioeconomic prospects of organisationally advanced manufacturing systems in the European Union. The results are as follows (Lehner, 1991):

-The development towards advanced systems in the Member States is slow and uneven.

-The introduction of new computer-aided production systems follows predominantly traditional production concepts putting the focus on the technology and keeping a high division of labour.

-Anthropocentric production systems are, however, developed in an increasing number of advanced implementations in different industries and different types of firms.

- Considerable differences are observed in industrial sectors in the development of APS. Generally speaking, development of APS is stronger in more competitive and technologically sophisticated industries.

-Differences between the core industrialised countries are, for the most part, gradual rather than fundamental.

\subsection{Obstacles for APS in industrialised countries}

Obstacles to the modernisation of industry towards APS are observed not only in the less industrialised member countries but also in the technical infrastructures of the industrialised countries:

-In all countries of the European Union, management strategies concerning the application of computer-based production technology are still predominantly orientated towards tayloristic production concepts.

-In some countries, manufacturing is still strongly characterised by standardised mass production while flexible, customer-oriented production is weak.

-In all countries of the European Union, rigidities in organisation, status systems and wage structures are widespread factors hindering the development of APS. -In many countries, e.g. in the United Kingdom, Spain and Portugal, shortages of skilled labour exist due to weak vocational training and further training. -In some countries, especially in the United Kingdom, France and Italy, low trust industrial relations impede the redesign of jobs and organisation.

The most important factors which might prevent the modernisation of manufacturing industry concerns the lack of awareness of the benefits, and a lack of knowledge and experience which have, up to now, not led to an 'APS culture' which can continue and further develop on its own. 


\subsection{The European Union and new manufacturing concepts}

In view of world market pressures on the European economy, action is demanded from the European Public Authorities. This has to be stipulated, although industry has to solve manufacturing problems itself and in the light of 'socio-cultural' aspects of manufacturing and the spirit of subsidiarity in a double sense: the state should not touch the industrial firms' autonomy and the European Union should not hurt the autonomy of the national industrial relations. Nonetheless, Member States should be made aware of the large differences between them in the production modes in order to maintain a decent competitive international level which has not only its 'hard', but also its 'soft side' which is the industrial culture. A first and fundamental step might be the awareness in the engineering community in order to build the proper foundation for further development.

\section{REFERENCES}

Brandt, D. (1991) Advanced Experiences with APS Concepts: Design strategies, Experiences - 30 European Case Studies, FAST occasional paper 246, Brussels: Commission of the European Communities.

Campbell, A., Sorge, A. and Warner. M. (1989) Microelectronic Product

Applications in Great Britain and West-Germany, Aldershot: Avebury.

Cooley, M., d'Iribarne, A., Martin, T., Ranta, J. and Wobbe. W, (1990) European

Competitiveness in the 21st Century: Integration of Work, Culture and

Technology, FAST occasional paper 245, Brussels: Commission of the European Communities.

Fujimoto, T. (1994) The Limits of Lean Production. On the Future of the Japanese Automobile Industry, in: Internationale Politik and Gesellschaft, $\mathrm{Nr}$. 1, s. 40-46.

Haywood, B. and Bessant, J. (1990) Organisation and integration of production systems, in: M. Warner, Wobbe, W. and Brödner, P. (Eds) New Technology and Manufacturing Management: Strategic Choices for Flexible Production Systems. Chichester: Wiley. pp. 75-85

Kageyama, K. (1993) R\&D and productivity in Japanese corporate groups, in: Wobbe, W. (Ed.) With assistance of M. Nakashima. The Future of Industry in the Global Context: Volume III - Management \& Manufacturing. FAST occasional paper 357, Brussels: Commission of the European Communities. pp. 97-102.

Kidd, P. T. (1990) Organisation, People and Technology in European

Manufacturing. FAST occasional paper 247, Brussels: Commission of the European Communities.

Lehner, F; (1991) Anthropocentric Production Systems: The European Response to Advanced Manufacturing and Globalisation, FAST occasional paper 248, Brussels: Commission of the European Communities.

Wobbe, W. (1991) Anthropocentric Production Systems: A Strategic Issue for Europe, FAST occasional paper 245, Brussels: Commission of the European Communities.

Womack, J.P., Jones, D.T. and Roos, D. (1990) The Machine that Changed the World, New York: Rawson Associates. 